Eixo Temático: Relação entre Ciência, Educação e Cultura

ET-05-002

\title{
PLANTAS MEDICINAIS TRAZIDAS DA ÁFRICA PARA O BRASIL: AFRICANIZANDO O BRASIL
}

Juma Gomes da Silva ${ }^{1,2}$, André Bernandes Pinheiro da Silva ${ }^{1,3}$, Ariane Rodrigues Muniz ${ }^{1,4}$, Luciana Maria de Oliveira Souza ${ }^{1,5}$, Eltamara Souza da Conceição ${ }^{6}$

${ }^{1}$ Bolsista ID PIBID-UNEB/CAPES. Universidade do Estado da Bahia. DCET II - Campus de Alagoinhas. Rod. Alagoinhas-Salvador, BR 100, KM 03, CEP: 48040-210.

2mel.haney@hotmail.com.br, 33andrebps@outlook.com, 4arianny.rodrigues@hotmail.com, ${ }^{5}$ luciana.souza1@hotmail.com.

${ }^{6}$ Coordenadora de Área PIBID-UNEB/CAPES. Universidade do Estado da Bahia. DCET II Campus de Alagoinhas. Rod. Alagoinhas-Salvador, BR 100, KM 03, CEP: 48040-210. elta_mara@yahoo.com.br.

http://dx.doi.org/10.21472/congrebio2016.et-05-002

\section{RESUMO}

Com o intuito de possibilitar a construção de uma opinião crítica, aliando senso comum ao conhecimento cientifico nos educandos do Colégio Estadual Luiz Navarro de Brito em Alagoinhas-Ba, através do Projeto PIBID/Subprojeto Interdisciplinar Ciências Biológicas/Matemática - Campus II - UNEB. Além disso, ampliar os conhecimentos sobre as espécies vegetais trazidas da África pelos negros durante o tráfico negreiro no Brasil foi desenvolvido o presente estudo. No mês de novembro é comemorada o dia nacional da consciência negra com o propósito de ressaltar a resistência negra durante o período de escravidão. Assim, os bolsistas ID realizaram um minicurso abordando o aculturamento negro no Brasil, a partir do uso das plantas medicinais, fato que vem contribuindo, nos dias atuais, para a valorização da cultura afrodescendente no nosso país. Durante o minicurso, os educandos foram instigados a fazer uma análise crítica do processo de escravidão, relacionando o conhecimento cientifico a cerca da utilização e identificação das plantas medicinais, ao seu uso na medicina popular. Dentre as plantas estudadas, destaca-se o dendezeiro (Elaeis guineenses Jacq.), a mamona (Ricinus communis L.), a jaqueira (Artocarpus integrifolia), o tamarinheiro (Tamarindus indica L.), o inhame (Dioscova cayenensis), o quiabo (Abelmoschus esculentus), a babosa (Aloe vera (L.) Burm. f.) e espada de São Jorge (Sansevieria trifasciata). Essas espécies são amplamente utilizadas atualmente para fins alimentícios, medicinais e econômicos, têm ocorrência no Brasil, sendo nativas da África. Isso reitera a grande influência, persistência e relevância da cultura africana no nosso país.

Palavras-chave: Afrodescendência; Plantas; Consciência negra.

\section{INTRODUÇÃO}

Com a vinda dos africanos para o Brasil, após três séculos do tráfico escravo, muitas foram as espécies vegetais trazidas, substituídas por outras de morfologia externa semelhante, enquanto algumas foram levadas daqui para o continente africano (ALMEIDA, 2011). Percebese que tanto o processo de escravidão como de abolição dos escravos sequestrados no continente africano e trazidos para Brasil, acarretou em uma troca mútua de espécies vegetais, garantindo assim o compartilhamento entre culturas. 
O costume de cultivar e usar essas plantas medicinais foi, e continua sendo, propagado pelas diferentes culturas. "Os conhecimentos tradicionais sobre o uso dos vegetais podem ser resgatados pela etnobotânica” (SOUZA e FELFILI, 2006).

No Brasil, quando os europeus aqui chegaram, se depararam com uma ampla quantidade de plantas medicinais aproveitadas pelos índios locais e esses conhecimentos eram resguardados pelos pajés. Os escravos africanos também deram valiosas contribuições sobre 0 uso de plantas trazidas da África, sendo muitas dessas utilizadas em rituais religiosos (LORENZI e MATOS, 2008). Assim, percebe-se que a utilização das plantas medicinais não é originária da África, mas todos os povos tradicionais da antiguidade já faziam uso das espécies vegetais presentes no meio em que estavam inseridos. No Brasil, o uso das plantas medicinais teve influência tanto das culturas indígena, africana, quanto europeia (JORGE, 2008).

Oliveira (2007 apud Meira, 2013) trata da ancestralidade e cultura, ressaltando que:

A ancestralidade converte-se no princípio da educação. Educar o olhar é Educação. No caso da cosmovisão africana, educa-se para a sabedoria, para a filosofia da terra, para a ética do encantamento. Educar é conhecer a partir das referências culturais. Olhar é um treino de sensibilidade. Aguça-se a sensibilidade para perceber o encanto que tece as coisas. Sensibilizado, o outro deixa de ser apenas um conceito, e me interpela para uma ação de justiça e me convida a uma conduta ética. Sensibilizado posso fazer da vida uma obra de arte na criatividade e na tradição.

Devido à importância da cultura acima referenciada, sobretudo do legado cultural deixado pela ancestralidade africana no Brasil, o presente estudo teve como objetivo discutir a forte influência da herança cultural africana na medicina popular do Brasil, possibilitando dessa forma, a construção de uma opinião crítica a cerca do aculturamento africano, relacionando o senso comum ao conhecimento cientifico nos educandos da Educação Básica, bem como realizar a identificação de espécies vegetais trazidas da África pelos negros no processo de tráfico negreiro.

\section{METODOLOGIA}

O minicurso ocorreu em dois turnos: matutino com uma turma do $1^{\circ}$ ano do ensino médio e vespertino, com duas turmas, uma do curso técnico em alimentos e outra do $2^{\circ}$ ano do ensino médio.

No primeiro momento iniciou-se o minicurso a partir de uma atividade dinâmica denominada "Desenrolando". Onde os educandos se espalhavam pela sala e em seguida davam as mãos, ficando enrolados uns nos outros. Em seguida a equipe tratava de se desenrolar. Isso foi feito para que houvesse uma reflexão acerca da vivencia das pessoas inseridas em comunidades tradicionais, valorizando o espírito cooperativo. Uma vez que é imprescindível abordar plantas medicinais sem citar as comunidades tradicionais, detentoras do conhecimento sobre a utilização desses recursos naturais.

Posteriormente, os educandos foram instigados pelos pibidianos a refletir sobre o transporte transatlântico de escravos, que perdurou por quase quatro séculos no Brasil. Isso foi representado a partir da utilização de barquinhos confeccionados com cartolina, contendo informações sobre a origem do processo de escravidão e o tráfico transatlântico. Nesta oportunidade foram ressaltados fatos importantes relacionados a diversos aspectos como: 0 sofrimento dos escravos, condições dos tumbeiros, condições de trabalho, atos de resistência, a proibição do tráfico negreiro, além da desmitificação de alguns elementos relacionados ao Continente Africano. Para essa atividade, os estudantes foram divididos em seis equipes, cada uma com dois barquinhos informativos. Ao realizar a leitura dos barquinhos ocorria a discussão em torno de cada problema apresentado. 
Seguindo a sequência didática, com os conhecimentos adquiridos a partir da dinâmica dos barquinhos, os bolsistas ID solicitaram que os educandos produzissem cartazes que ressaltassem a consciência negra, sob a visão de cada equipe. Isso foi feito a partir de imagens retiradas de livros, jornais e internet, para posterior confecção de um mural.

Dando continuidade às tarefas, foi discutido sobre aspectos da cultura africana inserida no Brasil, a partir da utilização das plantas medicinais trazidas pelos negros. Para isso, foram utilizados recursos visuais (material in natura) das plantas, para identificação do nome popular. Posteriormente, procedeu-se com a identificação do nome cientifico e da família dessas plantas, com a utilização do jogo da identificação, usando fichas constando o nome popular, nome cientifico e da família de cada planta. Os educandos fizeram a identificação sob a orientação dos pibidianos.

A partir daí, procedeu-se a confecção de chás, banhos, emplastos e infusão, a fim de demonstrar as diferentes formas de preparo e uso das plantas tidas como medicinais, ressaltando os problemas relacionados ao uso indiscriminado desses recursos vegetais e ao fato de que algumas plantas não podem ser ingeridas. Justificando-se assim sua utilização apenas em banhos e emplastos. Durante a atividade, ressaltou-se também o valor simbólico das plantas, as quais são utilizadas para os ditos "males do tempo", como olhado, olho grosso, inveja e proteção.

A culminância foi feita com a degustação de chás e sucos, a partir de algumas das plantas estudadas, além da exposição de todo material confeccionado.

\title{
RESULTADOS E DISCUSSÃO
}

Durante a dinâmica de socialização, percebeu-se que os discentes estavam introvertidos e o principal objetivo da dinâmica foi alcançado, que consistia na integração entre eles. A partir dessa socialização, foi mais fácil trabalhar a dinâmica das comunidades tradicionais, sobretudo porque esta é baseada no cooperativismo, na ajuda ao próximo e os discentes precisavam incorporar esse espírito de cooperativismo. Reiterando-se que para tratar da temática plantas medicinais, torna-se necessário fazer referências às comunidades tradicionais e suas características, sobretudo porque são elas as detentoras do conhecimento voltado para a medicina popular. Isso é amplamente difundido, por exemplo, Almeida (2011) cita que:

\begin{abstract}
Os levantamentos etnomédicos realizados demonstram a forte influência da herança cultural africana na medicina popular do Brasil, principalmente no norte, nordeste e sudeste do país. A manutenção da herança africana em vários âmbitos socioculturais brasileiros é, antes de tudo, uma forma de resistência de uma camada mestiça da população.
\end{abstract}

Já na dinâmica dos barquinhos informativos, o debate sobre os motivos que levaram os europeus à busca de mão-de-obra escrava, devido à expansão marítima, foi relevante para o entendimento dos educandos sobre o assunto, bem como para entenderem a forma desumana com que ocorria o sequestro dos povos africanos, a sofrida e angustiante rota de travessia do transatlântico, as revoltas e fugas ocorridas pelos negros escravizados, as severas punições sofridas e a influência da cultura trazida por esses povos de diferentes países daquele continente. Na fala de Santos (2011), é possível analisar o quão desumano era o tráfico transatlântico:

Pense agora em um navio negreiro. Pense em suas galerias fétidas, sujas, modorrentas, apertadas, úmidas, eivadas de correntes enferrujadas e cheias de insetos e ratazanas disputando o espaço em que centenas de africanos se espremiam, nus, atônitos, famintos, humilhados e feridos pelo aprisionamento (SANTOS, 2011). 
Com isso, foi verificado pelos pibidianos, que os educandos se expressavam de forma crítica em relação a cada assunto abordado durante os debates, que surgia em cada sequência de atividade desenvolvida.

O sequestro dos negros de vários países do Continente Africano pode ser verificado a partir da citação de Ramos (1946):

Chegou aqui uma aluvião de negros escravos, provindos da Guiné, do Congo, de São Tomé, da Costa da Mina, mais tarde de Moçambique e de outros pontos da África. E em todo o século XVI, XVII, XVIII, os negros africanos aqui entraram (RAMOS, 1946).

Houve uma exposição dos educandos, de suas opiniões, de forma critica, durante todo o debate, com opiniões diversas, sempre relacionadas às informações obtidas durante a atividade proposta.

Durante a produção de cartazes sobre o tema, os educandos escolheram abordar sobre os negros na mídia, a conquista dos negros no mercado de trabalho, a beleza negra, a moda negra, preconceito e racismo, dentre outros temas relevantes da história do negro no país.

Após o debate, bem como os esclarecimentos sobre as dúvidas pendentes, iniciaram-se as atividades de identificação das plantas. Nessa ocasião, foi enfatizado que, durante os sequestros, os negros escravizados traziam o pouco da sua cultura para diminuir o que chamavam de "banzo" (melancolia), ocasionado pela saudade da sua terra e do seu povo (ALMEIDA, 2011). Por isso traziam essas plantas tidas como medicinais que eram seus únicos meios de tratamento médico na cura das diversas enfermidades (BASTIDE, 2001).

Não apenas havia, como há relação e uso das plantas com finalidade religiosa. Como afirma Bastide (2001), “o culto aos deuses era um verdadeiro microcosmo da terra ancestral”. Isso é feito ainda hoje em cultos religiosos, a partir da utilização das plantas.

Dentre as plantas estudadas (Quadro 1), destacamos o dendezeiro (Elaeis guineenses Jacq.), mamona (Ricinus communis L.), jaqueira (Artocarpus integrifolia), tamarinheiro (Tamarindus indica L.), inhame (Dioscova Cayenensis), quiabo (Abelmoschus esculentus), a babosa (Aloe vera (L.) Burm. f.) e espada de São Jorge (Sansevieria trifasciata), todas de ampla utilização na culinária e também para fins medicinais. Verifica-se então que há uma diversidade de plantas de uso comum no nosso cotidiano, que foram trazidas do Continente Africano, mas que daqui pra lá, também houve o transporte de plantas de origem americana. Segundo Almeida (2011), após a abolição, o chamado refluxo migratório de africanos e de seus descendentes, levou para a África o milho, o guiné, o pinhão branco, a batata doce, o fumo e algumas espécies de Annonacea (pinha, fruta-do-conde e graviola). Já as espécies africanas como a mamona, dendê, quiabo, inhames, tamarineiro e jaqueira, bem adaptadas aqui, tornaram-se espontâneas no Brasil (ALMEIDA, 2011). Portanto, verifica-se o fluxo constante de plantas por meio dos negros escravizados. 
Quadro 1. Plantas medicinais trazidas da África pelos escravos para o Brasil.

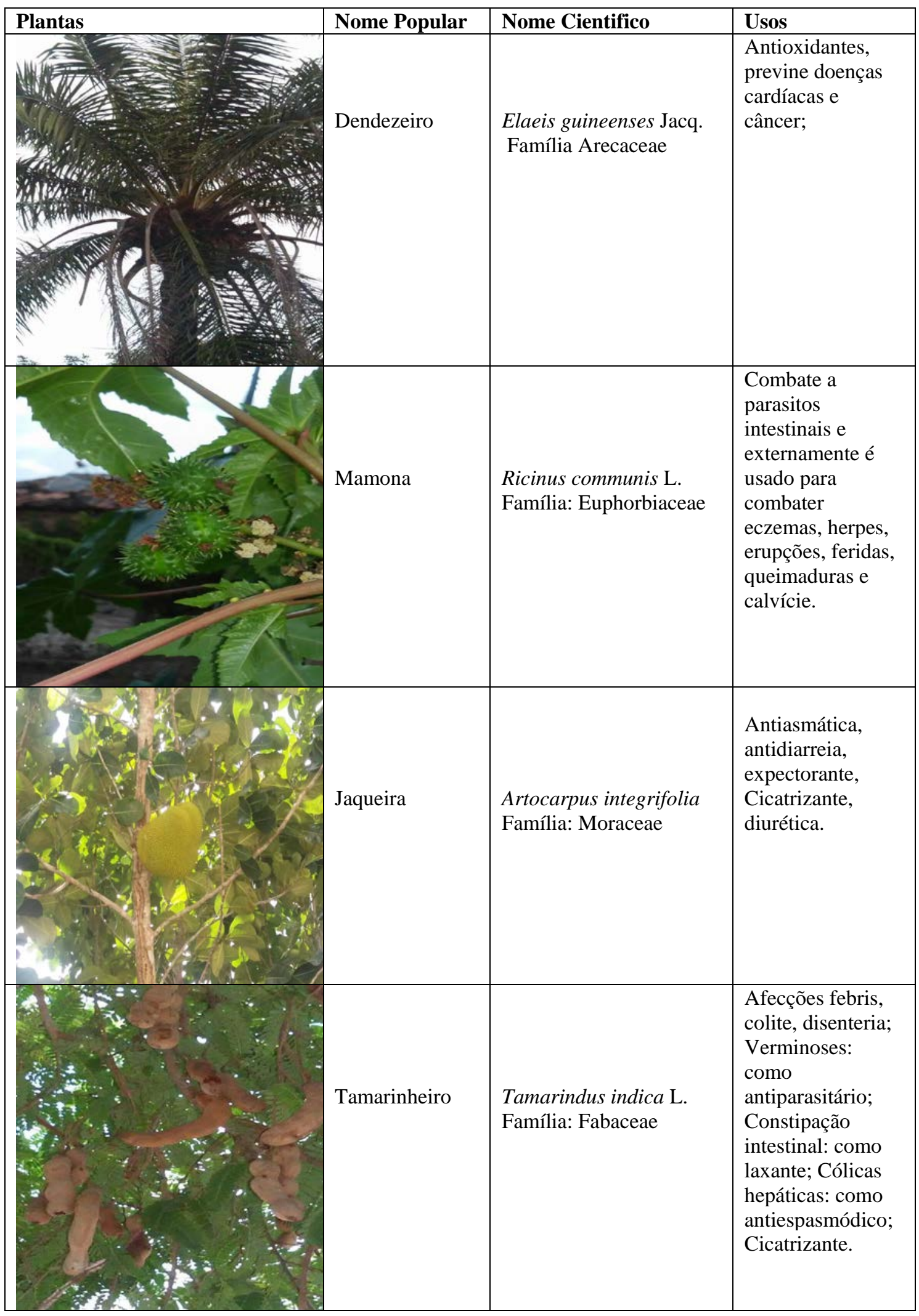


Quadro 1. Continuação.

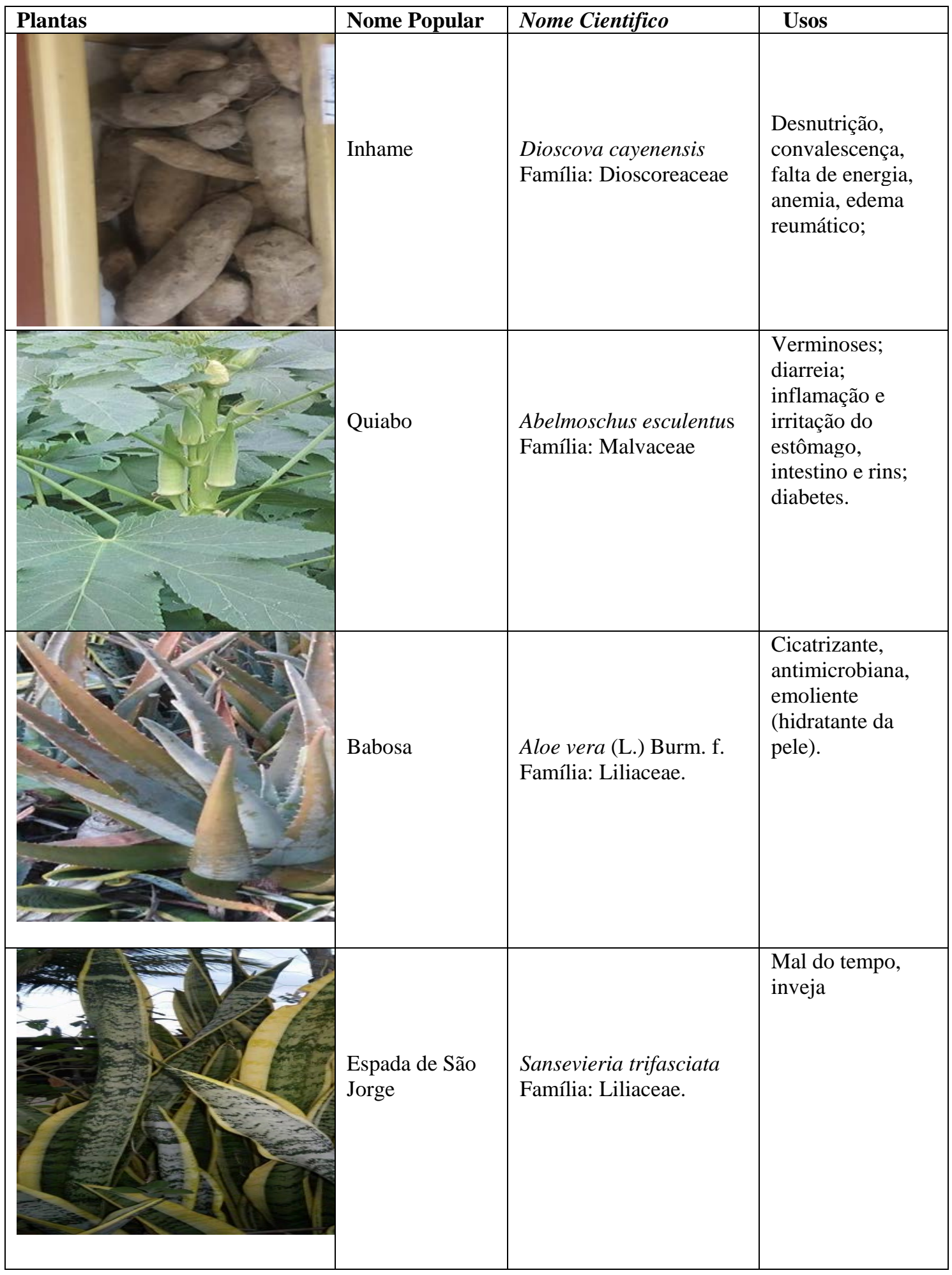

Segundo Luhning (2006), é provável que após a fase de reconhecimento e identificação das plantas brasileiras pelos escravos, tenha começado um movimento de intercâmbio entre Brasil e África no que se refere à troca de informações sobre as plantas comuns por aqui e as nativas daquele continente. 
Durante as atividades nas classes, foi observada, nos discentes, a sensibilização em relação ao conhecimento adquirido, pela relação estabelecida entre a existência de espécies vegetais tão comuns ao seu cotidiano e sua origem.

Já a confecção de chás, banhos, emplastos e infusão, permitiram aos educandos a associação entre a temática a sua realidade cotidiana, porque suas mães, avós e tias utilizam essa forma de tratamento alternativo na cura de determinadas enfermidades em casa. O uso popular de plantas medicinais nessas condições, constitui um complexo sistema de saúde não oficial, em que participam "erveiros", centros religiosos e comunidade. Durante muitos anos, esse sistema paralelo de terapêutica foi duramente criticado pela sociedade e até mesmo alvo de perseguição policial (ALMEIDA, 2011). Mas está cada vez mais sendo aceito, sobretudo pela valorização da cultura tradicional associada ao conhecimento científico, estabelecida pela etnobiologia.

Como afirma Bastide (2001 apud Meira, 2013), a África brasileira é sincrética, composta de negros, brancos e índios, e é dessa mistura que nasce a cultura afro-brasileira, híbrida por formação e trajetória. Isso representa muito o nosso país e explica a origem de nossa cultura, bem como, o conhecimento disso por mais pessoas, potencializa o sentimento de valor que cresce sobre a nossa origem.

\section{CONCLUSÕES}

É inegável a influência africana em relação à grande diversidade de plantas medicinais introduzidas no Brasil e a importância disso no aculturamento negro do país.

O conhecimento sobre a origem de recursos amplamente utilizados na medicina e culinária é relevante para sensibilizar as pessoas sobre a importância da cultura adotada no seu país e valorização dos povos que a introduziu.

As atividades desenvolvidas contribuíram amplamente para a sensibilização dos educandos da Educação Básica sobre a valorização da cultura afrodescendente, o que agora os permite refletir de forma significativa sobre a questão racial e a importância do respeito que se deve ter às pessoas de diversas raças e culturas.

\section{AGRADECIMENTOS}

Agradecemos ao PIBID-CAPES, pela concessão das bolsas de iniciação à docência e Coordenação de Área, que possibilitam a experiência de vivenciar a rotina dinâmica dos espaços escolares.

\section{REFERÊNCIAS}

ALMEIDA, M. Z. Plantas medicinais. 3. ed. Salvador: EDUFBA, 2011. Disponível em: $<$ https://repositorio.ufba.br/ri/bitstream/ri/5376/1/Plantas_medicinais_3ed_RI.pdf >. Acesso em: 02 abr. 2016.

BASTIDE, R. O candomblé da Bahia: rito nagô. São Paulo: Companhia das Letras, 2001.

JORGE, S. S. A. Plantas medicinais: coletânea de saberes. 2008.

LORENZI, H.; MATOS, F. J. A. Plantas medicinais no Brasil: nativas e exóticas. Nova Odessa: Instituto Plantarum, 2002.

LÜHNING, Â. E. As plantas brasileiras e seus parentes africanos. In: CAROSO, C.; BACELAR, J. (Orgs.). Faces da tradição afro-brasileira: religiosidade, sincretismo, antisincretismo, reafricanização, práticas terapêuticas, etnobotânica e comida. 2. ed. Rio de Janeiro, Salvador: Pallas, CEAO, 2006. p. 257-288. 
MEIRA, C. S. Plantas do axé e sua fundamentação religiosa: um estudo de caso no Terreiro de Umbanda "Caboclo Boiadeiro" (Fazenda Buraco do Boi - Poções/Bahia). Itapetinga: UESB, 2013.

OLIVEIRA, D. E. Filosofia da ancestralidade: corpo e mito na filosofia da educação brasileira. Curitiba: Gráfica Popular, 2007.

RAMOS, A. As culturas negras no novo mundo. 2. ed. Rio de Janeiro: Companhia Editora Nacional, 1946.

SANTOS, M. A. O. Negritudes Posicionadas: as muitas formas da identidade negra no Brasil. Perspectiva Sociológica, v. 3, p. 12-18, 2011.

SOUZA, C. D.; FELFILI, J. M. Uso de plantas medicinais na Região de Alto Paraíso de Goiás, GO, Brasil. Acta Bot. Bras., v. 20, n. 1, p. 135-142, 2006. Disponível em: <http://www.scielo.br/pdf/abb/v20n1/13.pdf>. Acesso em: 01 abr. 2016. 